\title{
The measurement of urinary gonadotropins for assessment and management of pubertal disorder
}

\author{
Laura Lucaccioni, ${ }^{1,2}$ Jane McNeilly, ${ }^{3}$ Avril Mason, ${ }^{1}$ Claudio Giacomozzi, ${ }^{4}$ \\ Andreas Kyriakou, ${ }^{1}$ Mohammed Guftar Shaikh, ${ }^{1}$ Lorenzo lughetti, ${ }^{2}$ Syed Faisal Ahmed ${ }^{1}$
}

${ }^{1}$ Developmental Endocrinology Research Group, Royal Hospital for Children, South Glasgow University Hospital Campus, University of Glasgow, Glasgow, United Kingdom; '2Post-graduate School of Paediatrics, Departments of Medical and Surgical Sciences of Mothers, Children and Adults, University of Modena \& Reggio Emilia, Paediatric Unit, Modena, Italy; ${ }^{3}$ Department of Biochemistry, Queen Elizabeth University Hospital, Glasgow, United Kingdom; ${ }^{4}$ Pediatric Unit, Pediatric Endocrinology Clinic Carlo Poma Hospital, Strada Lago Paiolo, Mantua, Italy

\begin{abstract}
OBJECTIVE: Measurement of urinary LH (uLH) and FSH (uFSH) may facilitate non-invasive pubertal assessment but there is a need for further validation by studying children and adolescents with disorders of puberty. DESIGN: 65 cases (Male: 25) with a median age of 12 years (2.9-18.1) supplied at least one non-timed urine sample for uLH and uFSH measurement by immunoassay and corrected for creatinine excretion. 25 cases were receiving GnRH-agonist (GnRH-a) at the time of sample collection. In 41 cases, urine samples were collected prior to a LHRH test and in 12 cases matched serum samples for basal LH (sLH) and FSH (sFSH) were also available. RESULTS: There was a significant correlation between sLH and uLH:uCr $(\mathrm{r}=0.82$; $\mathrm{p}$-value $<0.001)$ and sFSH and $\mathrm{uFSH}: \mathrm{uCr}(\mathrm{r}=\mathbf{0 . 9 3}$; $\mathrm{p}$-value $<0.001)$. Based on receiver operator characteristics analysis, a uLH:uCr value of $0.05 \mathrm{IU} / \mathrm{mmol}$ as a cut-off would detect a $\mathrm{LH}$ peak $>5 \mathrm{U} \mathrm{I} / \mathrm{L}$ with a sensitivity of $86 \%$ and a specificity of $72 \%$ with a positive predictive value of $93 \%$. In pubertal boys (6) and girls (22) with a sLH peak >5UI/L, median uLH:uCr was $0.27 \mathrm{IU} / \mathrm{mmol}(0.27-0.28)$ and $0.17 \mathrm{IU} / \mathrm{mmol}(0.09-0.43)$, respectively. The median uFSH:uCr was $0.51 \mathrm{IU} / \mathrm{mmol}(0.41-0.60)$ for boys and $1.1 \mathrm{IU} / \mathrm{mmol}(0.21-2.44)$ for girls. In the 25 cases on GnRH-a, the median uLH:uCr for boys and girls was $0.02 \mathrm{IU} / \mathrm{mmol}(0.01-0.02)$ and $0.02 \mathrm{IU} /$ mmol (0.004-0.07), respectively, and the median uFSH:uCr was $0.07 \mathrm{IU} / \mathrm{mmol}(0.05-0.09)$ and 0.27 IU/mmol (0.09-0.54), respectively. CONCLUSION: Urinary gonadotrophins reflect serum gonadotrophin concentration and may represent a reliable non-invasive method of assessing pubertal progress.
\end{abstract}

Key words: Disorders, FSH, Gonadotrophins, LH, Puberty

Address for correspondence:

Professor Syed Faisal Ahmed, MD, FRCPCH, Developmental Endocrinology Research Group, School of Medicine, University of Glasgow, Royal Hospital for Children, South Glasgow University Hospital Campus, 1345 Govan Road, Glasgow G51 4TF, United Kingdom; E-mail: Faisal.ahmed@glasgow.ac.uk Receive: 26-02-2016, Accepted: 23-06-2016

\section{INTRODUCTION}

The onset of pubertal development and the progression to full maturity is due to activation of the hypothalamic-pituitary-gonadal (HPG) axis through an increase in gonadotrophin-releasing hormone $(\mathrm{GnRH})$ pulsatility which leads to activation of the anterior 
pituitary to produce gonadotrophins, luteinising hormone (LH) and follicle-stimulating hormone (FSH). ${ }^{1}$ Biochemical assessment of pubertal activation of the HPG axis requires multiple blood samples with the assessment of LH and FSH before and after stimulation with GnRH-agonists (GnRH-a). These tests require a hospital visit and are expensive and invasive. Gonadotrophin-dependent central precocious puberty (CPP) is often managed by suppression of the HPG axis through the use of GnRH-a that are administered as depot injections at fixed intervals. ${ }^{2}$ Recently, a subcutaneous implant releasing the GnRHa histrelin at an average rate of $65 \mathrm{microg} /$ day was developed, with encouraging results., ${ }^{3,4}$ Monitoring of adequate suppression is usually based on an assessment of physical growth and puberty and the frequency of injections is often increased when these clinical parameters suggest inadequate suppression. Although there may be scope for further personalization of therapy, this has been difficult to achieve in the absence of objective and reliable tools that are simple, inexpensive and lend themselves to repeat measurements. With improvements in assays and the increasing need for non-invasive, out-patient based investigations, there has been renewed interest in the use of urinary gonadotrophins ( $\mathrm{uGn}$ ) for assessing pubertal progress. Recently, uGn have been reported to differentiate between healthy pre-pubertal and pubertal children. ${ }^{5,6}$ However, currently, there is a lack of evidence examining the utility of $\mathrm{uGn}$ for assessing disorders of puberty and for monitoring therapy that alters pubertal progress.

This study aims to investigate the relationship between serum (both basal and peak during the luteinising hormone releasing hormone (LHRH) stimulation test) and urinary $\mathrm{LH}(\mathrm{uLH})$ and $\mathrm{FSH}(\mathrm{uFSH})$ in young people undergoing investigation or management of pubertal disorders.

\section{SUBJECTS AND METHODS}

\section{Subjects}

Between December 2012 and July 2014, 65 cases with a median age of 12 years (age range 2.9-18.1) who were being evaluated for concerns regarding puberty at the Royal Hospital for Children, Glasgow, supplied a total of 117 non-timed spot urine samples as part of routine endocrine assessment. In 41 cases (Male: 18), a urine sample was collected immediately prior to a LHRH stimulation test and in another 12 (Male: 6) matched samples were also available for basal LH (sLH) and FSH (sFSH) determination. The 65 cases were referred for: early puberty (29), pubertal delay (27) [including constitutional delay (23) primary gonadal failure (2) and hypogonadotrophic hypogonadism (2)] and gender identity disorder (GID) (9) (Figure 1). A diagnosis of CPP, performed in 19 patients of those evaluated for early puberty, was based on a history of pubertal development at $<8$ years in girls and $<9$ years in boys, clinical signs of pubertal activation (breast bud in girls, testicular volume $>3 \mathrm{ml}$ in boys) and a LH peak $>5 \mathrm{IU} / \mathrm{L}$ on LHRH stimulation test. Early puberty was defined as clinical signs of pubertal activation but a stimulated LH peak $<5$ IU/L. Delayed puberty (DP) was considered in cases with no clinical and biochemical signs of pubertal activation in boys $>14$ years and in girls $>13$ years. ${ }^{7}$ In pubertal failure (hypogonadotrophic hypogonadism), a complete lack of response to LHRH stimulation test supported the diagnosis, while in primary gonadal failure, basal LH and FSH were elevated and their responses to LHRH were exaggerated. Samples were also collected as part of routine endocrine monitoring in a group of adolescents with a psychiatric diagnosis of GID undergoing treatment with GnRH-a. Treatment to suppress puberty was performed with Triptorelin (Decapeptyl SR, Ipsen, UK) at a dosage of 11.25

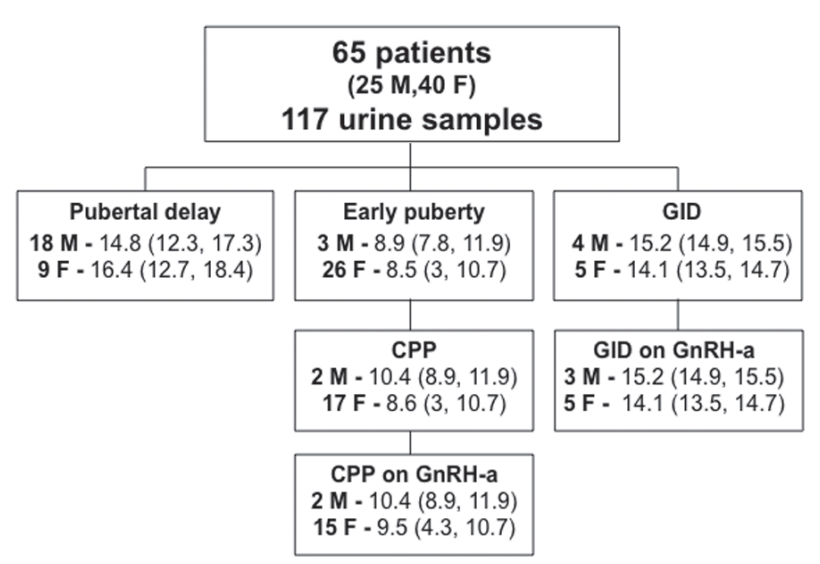

Figure 1. Main population characteristics. Age (years) at collection of urine sample is expressed as median (range). Subjects were categorised according to the main reason for investigation of puberty. 
mg every 10 or 12 weeks. Among the 19 cases with CPP and 9 with GID, 25 received GnRH-a therapy between December 2012 and July 2014.

\section{Anthropometry \& imaging}

Anthropometric measurements were performed by fully-trained examiners and converted into standard deviation score (SDS) using 1990 British children standards. ${ }^{8}$ Height was measured to the nearest $0.1 \mathrm{~cm}$ with a calibrated wall-mounted stadiometer (Harpenden, Crymych; UK) and weight was measured to the nearest $0.1-\mathrm{kg}$ with a calibrated scale. Pubertal status was classified according to Tanner staging. ${ }^{9}$ Bone age was assessed by $\mathrm{x}$-ray of the left hand and wrist using BoneXpert (Visiana Aps, Denmark). In girls, pelvic ultrasound was performed to assess uterine length, fundo-cervical ratio, endometrial stripe and ovarian volume. Magnetic resonance imaging (MRI) of the brain and pituitary was performed in all cases with a diagnosis of CPP to exclude organic causes. An LHRH test was performed in 41 patients using a standard procedure, which consisted of collection of blood samples for serum LH and FSH estimation at baseline and 20 and 60 minutes after intravenous administration of 100 micrograms of LHRH (HRF, Intrapharm Laboratories Ltd, UK).

\section{Gonadotrophin assays}

Non-timed plasma and urine samples were collected in the same period of the day, processed and stored at $-20^{\circ} \mathrm{C}$. Gonadotrophins were measured by a chemiluminescent microparticle immunoassay on the Architect ci8200 (Abbott Laboratories Diagnostics, IL, USA), as previously described. ${ }^{5}$ The lower limit of FSH and LH detection was $0.1 \mathrm{IU} / \mathrm{L}$ and inter- and intra-assay precision (coefficient of variation, $\mathrm{CV}$ ) for both LH and FSH were less than 5\% at levels of 0.2 and $2.3 \mathrm{IU} / \mathrm{L}$ for $\mathrm{LH}$ and 0.6 and $4.7 \mathrm{IU} / \mathrm{L}$ for FSH. Analytical sensitivity of the assays was $0.07 \mathrm{IU} / \mathrm{L}$ and $0.05 \mathrm{IU} / \mathrm{L}$ for LH and FSH, respectively. LH and FSH values $<0.1 \mathrm{IU} / \mathrm{L}$ were attributed an arbitrary value of $0.1 \mathrm{IU} / \mathrm{L}$ to facilitate analysis. Urinary creatinine was measured using the modified Jaffe method with a lower limit quantitation of $0.35 \mathrm{mmol} / \mathrm{L}$ : none of the samples had a urinary creatinine $<1.0 \mathrm{mmol} / \mathrm{L}$. FSH and LH results were corrected for creatinine (by dividing the $\mathrm{uGn}$ value for the corresponding creatinine value of each urine sample) and compared to previously published reference data that were analysed following the same storage and analysis process. ${ }^{5}$ Effect of storage temperature was assessed by dividing a single urine sample into three groups of 10 aliquots which where stored at room temperature (RT), $4^{\circ} \mathrm{C}$ or $-20^{\circ} \mathrm{C}$. A sample from each group was assayed for LH and FSH consecutively over 11 days. The CVs of the three groups for LH were $9.4 \% ; 8.6 \%$ and $7.8 \%$ for samples stored at RT, $4^{\circ} \mathrm{C}$ or $-20^{\circ} \mathrm{C}$, respectively. For FSH, the CVs were $8.2 \%, 6.5 \%$ and $5.9 \%$ for samples stored at RT, $4^{\circ} \mathrm{C}$ or $-20^{\circ} \mathrm{C}$, respectively. Additionally, a urine sample was stored at $-20^{\circ} \mathrm{C}$ and $-70^{\circ} \mathrm{C}$. Assays performed after 3 and 6 months yielded LH levels that were $88 \%$ and $83 \%$ at $-20^{\circ} \mathrm{C}$ and $89 \%$ and $86 \%$ of the original concentration at $-70^{\circ} \mathrm{C}$. Similarly, yielded FSH levels were $92 \%$ and $90 \%$ at $-20^{\circ} \mathrm{C}$ and $94 \%$ and $91 \%-70^{\circ} \mathrm{C}$ of the original concentration.

\section{Statistical analysis}

All data were expressed as median (range) and analysed using SPSSv10.0 (SPSS Inc., Chicago, IL, USA). Inter-group comparison for continuous variables was performed with the Mann-Whitney U test and correlation between variables was determined using the Spearman's correlation coefficient. A pvalue lower than 0.05 was considered statistically significant. Receiver operating characteristics (ROC) curves were performed for $\mathrm{LH}$ peak to select the cut-off value of $\mathrm{uLH}: \mathrm{uCr}$ that provided a $\mathrm{LH}$ peak $>5 \mathrm{IU} / \mathrm{L}$. In the ROC curve, the true positive rate (sensitivity) was plotted as a function of the false positive rate (1-specificity) to identify the cut-off values of the parameter of interest. ${ }^{10}$ Sensitivity and specificity were calculated using the area under the ROC curve.

\section{RESULTS}

\section{Correlation between urinary and serum gonadotrophins}

In the 53 cases where there were matched urine and basal serum samples, there was a strong association between $\mathrm{uLH}: \mathrm{uCr}$ and $\mathrm{sLH}(\mathrm{r}=0.83$, $\mathrm{p}$-value $<0.001)$ and $\mathrm{uFSH}: \mathrm{uCr}$ and $\mathrm{sFSH}(\mathrm{r}=0.93$, $\mathrm{p}$-value $<0.001)$. After removing two outliers who had primary gonadal failure, the association between urine and serum concentrations for LH and FSH was 0.82 (p-value $<0.001$ ) and 0.93 (p-value $<0.001$ ), respectively (Figure 2). 

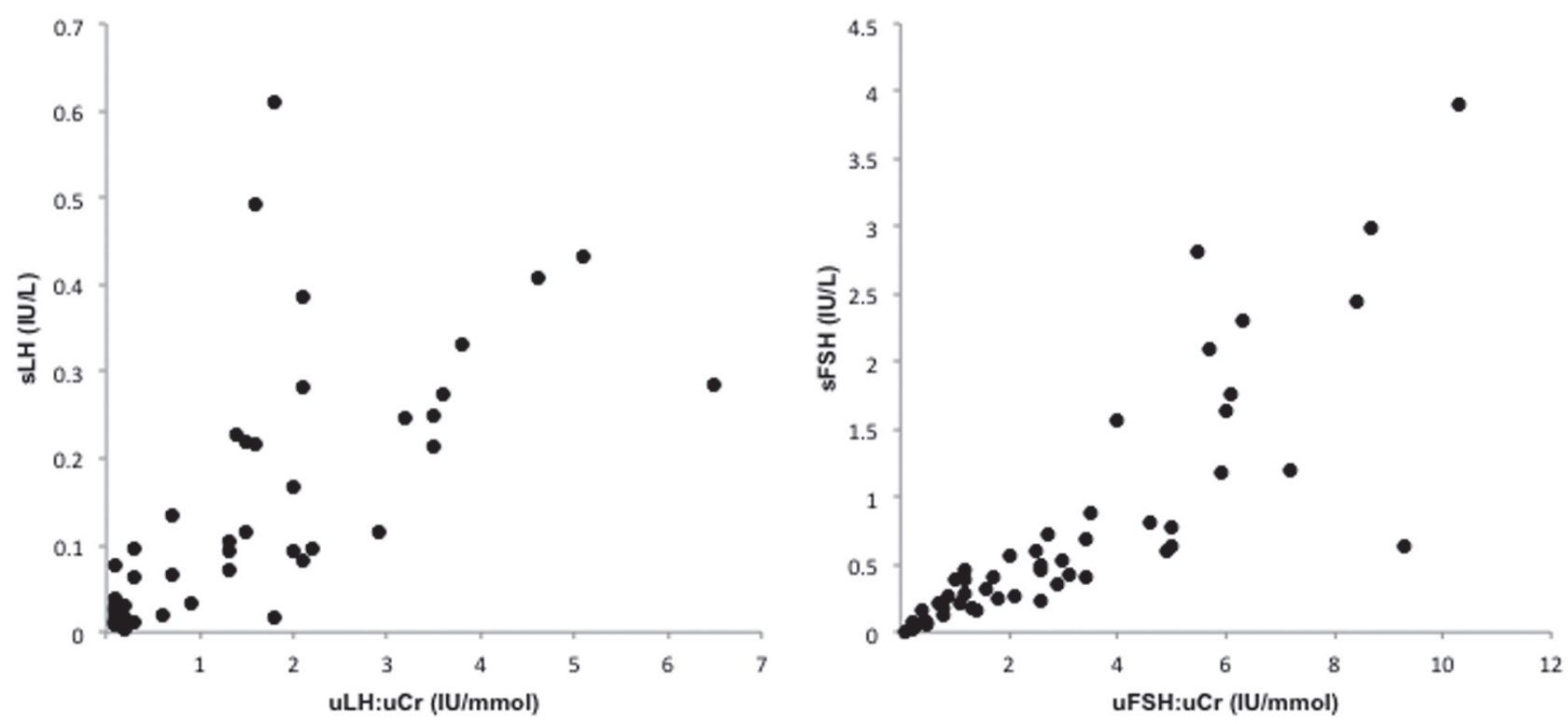

Figure 2. Correlation between serum gonadotrophins (sLH, sFSH) and urinary gonadotropins corrected for creatinine (uLH:uCr, uFSH:uCr). Significant associations were observed both for LH and FSH even after removing two outliers (two patients with primary gonadal failure referred for pubertal delay).

In 41 cases who had a LHRH stimulation test, the optimal uLH:uCr cut-off point that predicted a $\mathrm{LH}$ peak greater than $5 \mathrm{IU} / \mathrm{L}$ was $0.05 \mathrm{IU} / \mathrm{mmol}$ with a sensitivity of $86 \%$ and specificity of $71 \%$. The positive predictive value for a $\mathrm{LH}$ peak $>5 \mathrm{IU} / \mathrm{L}$ when $\mathrm{uLH}$ : $\mathrm{uCr}$ was $>0.05 \mathrm{IU} / \mathrm{mmol}$ was $93 \%$ (Figure 3 ).

\section{Pubertal delay}

The median $\mathrm{uLH}: \mathrm{uCr}$ for boys with pubertal delay was $0.12 \mathrm{IU} / \mathrm{mmol}(0.01,0.48)$ : this was significantly higher than the reference range for pre-pubertal boys at $0.01 \mathrm{IU} / \mathrm{mmol}(0.01,0.2)(\mathrm{p}$-value $=0.001)$ and within the reference range for pubertal boys ( $\mathrm{uLH}: \mathrm{uCr}$ $0.09 \mathrm{IU} / \mathrm{mmol}(0.01,0.28)$ (p-value=0.150). The median $\mathrm{uFSH}: \mathrm{uCr}$ for the boys with pubertal delay was $0.44 \mathrm{IU} / \mathrm{mmol}(0.01,9.9)$ and higher than the reference range for pre-pubertal boys at $\mathrm{uFSH}: \mathrm{uCr}$ $0.13 \mathrm{IU} / \mathrm{mmol}(0.004,1)(\mathrm{p}$-value $=0.003)$ and also for pubertal boys (uFSH:uCr $0.2 \mathrm{IU} / \mathrm{mmol}(0.02$, $0.7)$ ( $p$-value $=0.037)$. The median $\mathrm{uLH}: \mathrm{uCr}$ for girls with pubertal delay was $0.09 \mathrm{IU} / \mathrm{mmol}(0.01,1.37)$, higher than normal for pre-pubertal girls who had a median $\mathrm{uLH}: \mathrm{uCr}$ of $0.013 \mathrm{IU} / \mathrm{mmol}(0.01,0.08)$ $(p$-value $=0.006)$ and within the reference range for pubertal girls who had a median uLH:uCr of 0.09 IU/mmol $(0.01,1.1)$; (p-value $=0.592)$. The median

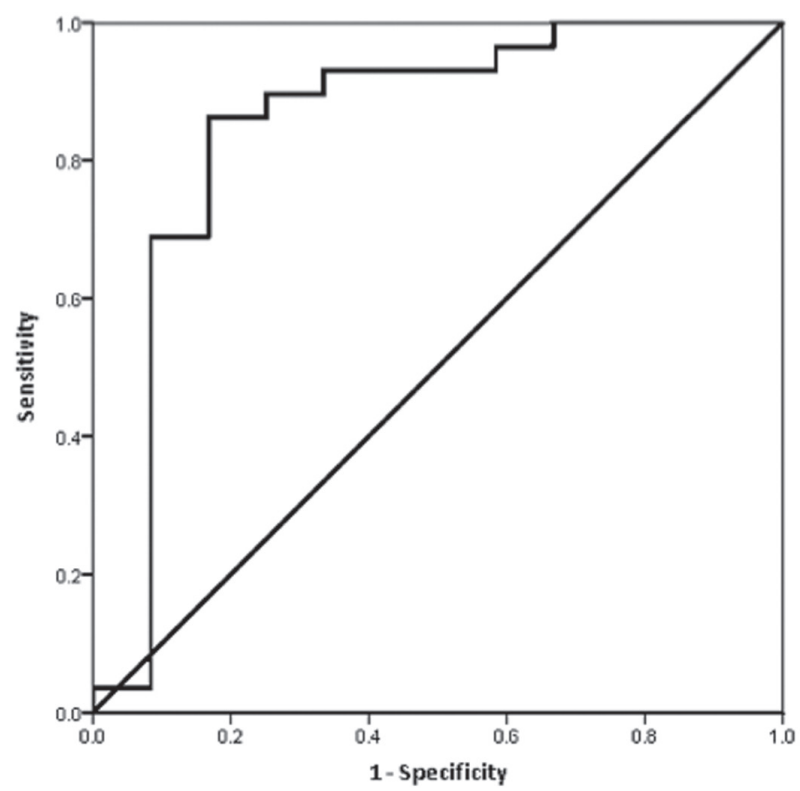

Figure 3. ROC curve for analysis of uLH:UCr cut-off point that predicted a LH peak greater than $5 \mathrm{IU} / \mathrm{L}$. In 41 cases who had a LHRH stimulation test, the optimal $\mathrm{uLH}$ :uCr cut-off point was $0.05 \mathrm{IU} / \mathrm{mmol}$ with a sensitivity of $86 \%$ and specificity of $71 \%$. The positive predictive value was $93 \%$.

uFSH:uCr for girls with pubertal delay was $0.71 \mathrm{IU} /$ $\mathrm{mmol}(0.01,16.1)$ : these values were significantly 
higher than the pre-pubertal reference range for prepubertal girls [uFSH:uCr - $0.45 \mathrm{IU} / \mathrm{mmol}(0.2,3.63)$ ] $(p$-value $=0.008)$ and within the reference range for pubertal girls $(p$-value $=0.233)$ (Figure 4$)$.

\section{Early puberty}

There were 9 girls and 1 boy within this category. The median $\mathrm{uLH}: \mathrm{uCr}$ for girls with early puberty was $0.03 \mathrm{IU} / \mathrm{mmol}(0.01,0.49)$ and similar to the pre-pubertal ( $\mathrm{p}$-value $=0.348)$ and pubertal ( $\mathrm{p}$-val$\mathrm{ue}=0.181$ ) reference range for girls (Figure 4). The median uFSH:uCr for girls with early puberty was $0.43 \mathrm{IU} / \mathrm{mmol}(0.11,3.91)$, close to the pre-pubertal $(p$-value $=0.167)$ and pubertal $(p$-value $=0.768)$ reference range for girls (Figure 4). uLH:uFSH ratio showed no significant difference compared to pre-pubertal and pubertal values.

\section{True central puberty}

This group consisted of 7 girls with CPP and 3 girls with GID. The median uLH:uCr for girls with central puberty not on GnRH-a treatment was 0.17 $\mathrm{IU} / \mathrm{mmol}(0.02,0.43)$ and significantly higher than the pre-pubertal reference range for pre-pubertal girls ( $p$-value $=0.010)$, but within the reference range for pubertal girls ( $p$-value $=0.418$ ) (Figure 4). The median uFSH:uCr for girls with central puberty not on GnRH-a treatment was $1.09 \mathrm{IU} / \mathrm{mmol}(0.21,2.44)$, significantly higher than the pre-pubertal reference range for pre-pubertal girls ( $\mathrm{p}$-value $=0.021$ ), but within the reference range for pubertal girls (Figure 4). The ratio, uLH:uFSH, did not show a difference significant in females compared both to pubertal and pre-pubertal values.

\section{True central puberty on GnRH agonist therapy}

This group consisted of 17 cases of CPP (2 males, 15 females) and 8 cases of GID ( 3 males, 5 female). The median uLH:uCr for boys and girls with true central puberty on GnRH-a treatment was $0.02 \mathrm{IU} /$
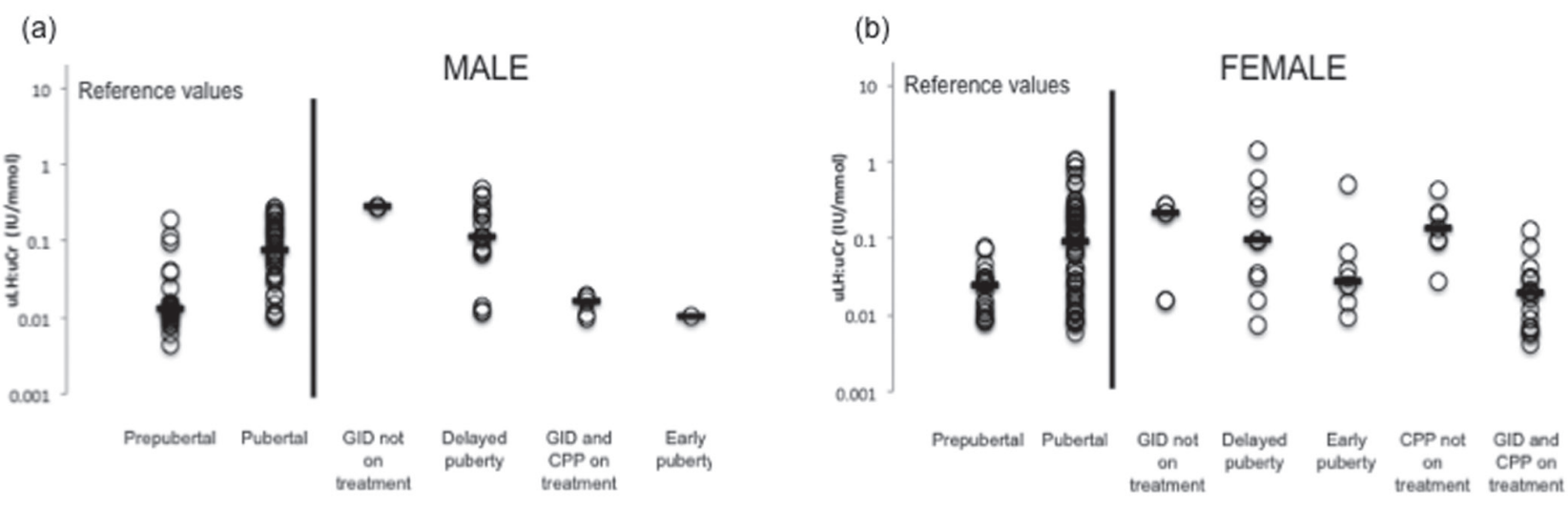

(c)

(d)
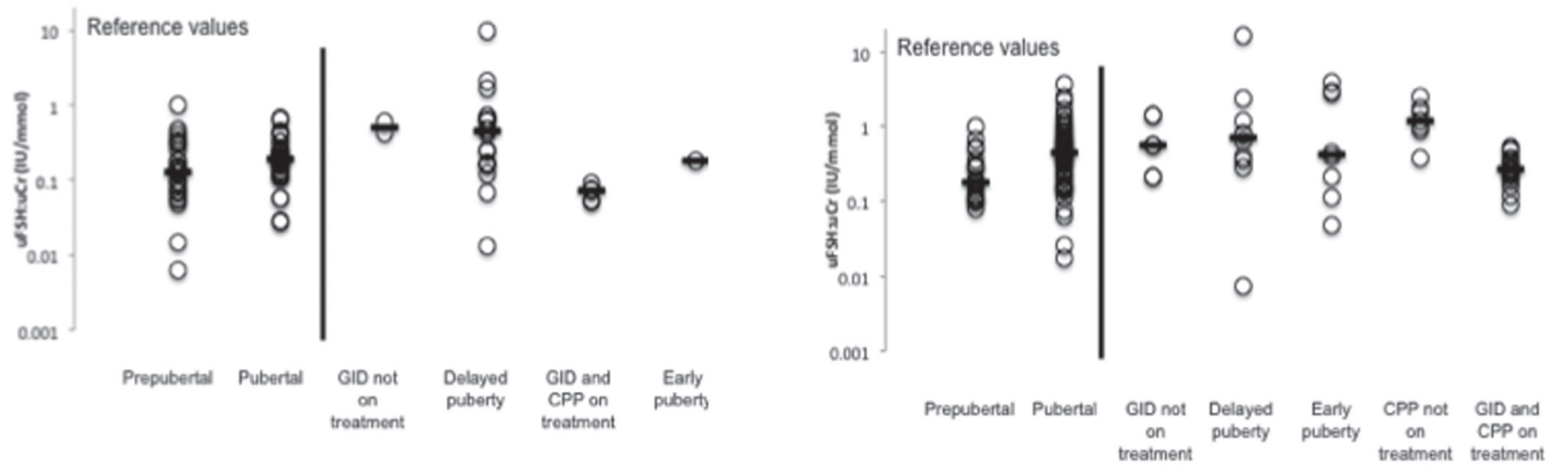

Figure 4. Data are shown as logarithmic scale. Median values are represented by the solid bar. Overall, the median levels of UGn increased with pubertal development and decreased with pubertal suppression both for male and female. 
$\mathrm{mmol}(0.01,0.02)$ and $0.02 \mathrm{IU} / \mathrm{mmol}(0.004,0.13)$, respectively, significantly lower than the pubertal reference range for pubertal boys ( $p$-value $=0.002$ ) and girls ( $p$-value $<0.001)$, but within the reference range for pre-pubertal boys and girls (Figure 4). The median uFSH:uCr for boys and girls with true central puberty on GnRH-a treatment was $0.07 \mathrm{IU} /$ $\mathrm{mmol}(0.05,0.09)$ and $0.27 \mathrm{IU} / \mathrm{mmol}(0.12,0.5)$, respectively, significantly lower than the pubertal reference range for pubertal boys ( $p$-value $<0.001$ ) and girls $(\mathrm{p}=0.009)$, but within the reference range for pre-pubertal boys and girls (Figure 4). uLH:uFSH ratio showed a difference significant both in male and female compared to pubertal values.

\section{DISCUSSION}

Disorders of puberty are commonly encountered in the field of endocrinology and its assessment routinely involves costly and invasive biochemical tests that require hospital attendance. ${ }^{11-14}$ Because of these limitations, children who undergo pharmacological pubertal suppression rarely undergo regular biochemical assessment of adequacy of the therapy. Whilst pubertal suppression by GnRH-a therapy is generally considered to be safe, ${ }^{15,16}$ it is possible that an improved knowledge of the extent of suppression may allow a more informed and customised treatment plan that is cheaper and more convenient for the child. Although measurement of $\mathrm{uGn}$ was described over four decades ago, ${ }^{17,18}$ its use in routine clinical management had not been considered until the relatively recent availability of more sensitive assays..$^{3,4,14}$

In this study of cases that were undergoing routine evaluation of puberty, the addition of $\mathrm{uGn}$ assessment has provided promising information regarding the clinical utility of this test for assessment and management of pubertal disorders. In a previous study aimed at creating reference ranges for healthy children, ${ }^{5}$ the lack of matched serum samples was considered to be a weakness and in the current study, the close correlation between $\mathrm{uGn}$ excretion and serum gonadotrophins in a range of conditions related to pubertal disorders confirms the reliability of $\mathrm{uGn}$ for reflecting serum levels. Moreover, ROC analysis confirmed that there is a strong correlation between $\mathrm{uGn}$ excretion and peak LH peak following LHRH stimulation test with high sensitivity and specificity, leading to the possibility that, although peak LH is commonly used to detect true puberty, uLH:UCr may become a useful alternative non-invasive method with a high diagnostic value.

The range of values for $\mathrm{uLH}: \mathrm{uCr}$ and $\mathrm{uFSH}: \mathrm{uCr}$ was very wide in those cases who had pubertal delay and the clinical utility of uGn would be questionable in that clinical scenario. However, in those with true puberty, uGn excretion was significantly higher than what would be expected in healthy pre-pubertal children, and in those cases of puberty who were on GnRH-a therapy, the mean uGn excretion was clearly within the pre-pubertal reference range. The clear fall in urinary excretion after initiating therapy suggests that this test could be used to monitor and titrate therapy more objectively than simple clinical examination and assessment of growth rate. Regular blood tests to check basal oestradiol and gonadotophins in combination with pelvic ultrasound and bone age assessment are often recommended to identify cases of progressive CPP. ${ }^{7}$ Prospective studies are now required to confirm the role of $\mathrm{uGn}$ instead of serum gonadotrophins for monitoring adequacy of treatment.

It is possible that the wide range of values in the delayed puberty group reflected the non-standardised timing of the collection of the urine samples, given that $\mathrm{uGn}$ concentrations would have been expected to have been higher in the morning samples rather than those collected later in the day. ${ }^{17,19}$ Nocturnal pulsatile secretion of gonadotrophins starts about two years before physical manifestations of pubertal onset and would have been more effectively detected in the first morning urine samples. ${ }^{1,20}$

However, the non-standardised collection utilised did not restrict the usefulness of $\mathrm{uGn}$ in the assessment of early or precocious puberty. The female patient with the highest values of gonadotrophins both in blood and urine was diagnosed as having primary ovarian failure, confirming the hypothesis that $\mathrm{uGn}$ could be a useful method to differentiate and screen a range of disorders of the HPG axis. Recent reports in children with early puberty have suggested that uGn excretion can differentiate between those with slowly-progressive and rapidly-progressive precocious puberty. ${ }^{21}$ 
The value of performing LHRH stimulation in all suspected cases of early puberty has been questioned recently ${ }^{21}$ and it would indeed be beneficial to consider a more convenient alternative or screening test. In the current study, there was the impression that $\mathrm{uGn}$ excretion was higher in those with true puberty, characterised by a peak $\mathrm{LH}$ of $>5 \mathrm{U} / \mathrm{L}$ on LHRH stimulation, compared to other cases with early puberty with a peak $\mathrm{LH}$ of $<5 \mathrm{U} / \mathrm{L}$; however, the number of cases in the latter group were not high enough to statistically confirm this difference.

It is possible that $\mathrm{uLH}: \mathrm{uCr}$ and $\mathrm{uFSH}: \mathrm{uCr}$ have different clinical utilities. For instance, while uLH:uCr concentration may have a role in distinguishing CPP from other forms of early puberty, ${ }^{22,23}$ the uFSH:uCr assessment may be useful for identifying cases of germ cell failure such as primary ovarian failure and Sertoli cell dysfunction. ${ }^{24-26}$ ULH:uFSH ratio may also be a useful parameter in cases of early puberty to differentiate between different forms of puberty, but this requires further exploration. In the current study, the groups of boys and girls studied had a wide range of pathologies and future studies should consider studying homogenous groups; standardizing the data for age and sex will also increase the utility of this tool.

In summary, this preliminary study suggests that $\mathrm{uGn}$ excretion may be a valuable method of differentiating between pre-pubertal and pubertal children and its measurement could also be used for non-invasive monitoring of the effectiveness of GnRH-a therapy.

\section{ACKNOWLEDGEMENTS}

We want to thank the paediatric endocrine nurses of the Royal Hospital for Children of Glasgow, Ethel McNeil and Victoria Fisher, for help with data collection.

\section{GRANT AND FELLOWSHIP SUPPORT}

Not applicable.

\section{CONFLICT OF INTEREST}

The authors declare that they have no conflict of interest.

\section{REFERENCES}

1. Grumbach MM, Styne DM 1998 Puberty: Ontogeny, neuroendocrinology, physiology, and disorders. In: Saunders WB (eds). Williams Textbook of Endocrinology, 9th edition. Philadelphia; pp, 1509-1625.

2. Carel JC, Eugster EA, Rogol A, et al, 2009 Consensus statement on the use of gonadotropin-releasing hormone analogs in children. Pediatrics 123: e752-762.

3. Hirsch HJ, Gillis D, Strich D, et al, 2005 The histrelin implant: a novel treatment for central precocious puberty. Pediatrics 116: e798-e802.

4. Silverman LA, Neely EK, Kletter GB, et al, 2015 Longterm continuous suppression with once-yearly histrelin subcutaneous implants for the treatment of central precocious puberty: a final report of a phase 3 multicenter trial. J Clin Endocrinol Metab 100: 2354-2363.

5. McNeilly JD, Mason A, Khanna S, Galloway PJ, Ahmed SF, 2012 Urinary gonadotrophins: a useful non-invasive marker of activation of the hypothalamic pituitarygonadal axis. Int J Pediatr Endocrinol 2012: 10.

6. Qi Y, Li P, Zhang Y, et al, 2012 Urinary metabolite markers of precocious puberty. Mol Cell Proteomics doi: 10.1074/mcp.M111.011072.

7. Carel JC, Leger J, 2008 Clinical practice. Precocious puberty. N Engl J Med 358: 2366-2377.

8. Freeman JV, Cole TJ, Chinn S, Jones PR, White EM, Preece MA, 1990 Cross sectional stature and weight reference curves for the UK. Arch Dis Child 73: 17-24.

9. Marshall WA, Tanner JM, 1969 Variations in pattern of pubertal changes in girls. Arch Dis Child 44: 291-303.

10. Zweig MH, Campbell G, 1993 Receiver-operating characteristic (ROC) plots: a fundamental evaluation toll in clinical medicine. Clin Chem 39: 561-577.

11. Partsch CJ, Heger S, Sippell WG, 2002 Management and outcome of central precocious puberty. Clin Endocrinol 56: 129-148.

12. Dixon JR, Ahmed SF, 2007 Precocious puberty. Paediatrics and Child Health 17: 343-348.

13. Kim HK, Kee SJ, Seo JY, Yang EM, Chae HJ, Kim CJ, 2011 Gonadotropin-releasing hormone stimulation test for precocious puberty. Korean J Lab Med 31: 244-249.

14. Zung A, Burundukov E, Ulman M, Glaser T, Zadik Z, 2015 Monitoring gonadotropin-releasing hormone analogue (GnRHa) treatment in girls with central precocious puberty: a comparison of four methods. J Pediatr Endocrinol Metab 28: 885-893.

15. Lazar L, Lebenthal Y, Yackobovitch-Gavan M, et al, 2015 Treated and untreated women with idiopathic precocious puberty: BMI evolution, metabolic outcome, and general health between third and fifth decades. J Clin Endocrinol Metab 100: 1445-1451.

16. Thornton P, Silverman LA, Geffner ME, Neely EK, Gould E, Danoff TM, 2014 Review of outcomes after cessation of gonadotropin-releasing hormone agonist treatment of girls with precocious puberty. Pediatr Endocrinol Rev 11: 306-317. 
17. Buckler JMH, Clayton BE, 1970 Output of luteinizing hormone in the urine of normal children and those with advanced sexual development. Arch Dis Child 45: 478-484.

18. Witchel SF, Benson RG, Lee PA, 1996 Treatment of central precocius puberty: comparison of urinary gonadotropin excretion and gonadotropin releasing hormone (gnrh) stimulation tests in monitoring GnRH analog therapy. J Clin Endocrinol Metab 81: 1353-1356.

19. Dunkel L, Alfthan H, Stenman UH, Tapanainen P, Perheentupa J, 1990 Pulsatile secretion of LH and FSH in prepubertal and early pubertal boys revealed by ultrasensitive time-resolved immunofloruometric assay. Pediatr Res 27: 215-219.

20. Dunger DB, Villa AK, Matthews DR, et al, 1991 Pattern of secretion of bioactive and immunoreactive gonadotrophins in normal pubertal children. Clin Endocrinol 35: 267-275.

21. Zung A, Burundukov E, Ulman M, et al, 2014 The diagnostic value of first-voided urinary LH compared with GnRH-stimulated gonadotropins in differentiating slowly-progressive from rapidly progressive-precocious puberty in girls. Eur J Enodcrinol 170: 749-758.

22. Cheetham T, 2014 Simplifying and refining the assessment of early puberty. Arch Dis Child 99: 3-4.

23. Iughetti L, Lucaccioni L, 2014 Precocious pubertal development: a challenge for pediatric endocrinologists. Expert Rev Endocrinol Metab 10: 1-3.

24. Nathwani NC, Hindmarsh PC, Massarano AA, Brook CG, 1998 Gonadotrophins pulsatility in girls with Turner Syndrome: modulation by exogenous sex steroids. Clin Endocrinol 49: 107-113.

25. Quigley CA, 2002 Editorial: The postnatal gonadotropin and sex steroid surge-insight from the androgen insensitivity syndrome. J Clin Endocrinol Metab 87: 24-28.

26. Ahmed SF, Cheng A, Hughes AI, 1999 Assessment of the gonadotrophin-gonadal axis in androgen insensitivity syndrome. Arch Dis Child 80: 324-329. 